120th ASEE Annual Conference \& Exposition

Paper ID \#7237

\title{
Analysis of Biodiesel Production and its Derivatives for a College Campus
}

Emilia Golebiowska

Mr. Giovanni Kelly II

Dr. Yassir M. Samra

Dr. James P Abulencia, Manhattan College 


\title{
ANALYSIS OF BIODIESEL PRODUCTION AND ITS DERIVATIVES FOR A COLLEGE CAMPUS
}

\begin{abstract}
$\underline{\text { Abstract }}$
In the Fall of 2010, XXXXX College started to devise and develop plausible green initiatives spearheaded by students across all five of its schools. From this college-wide endeavor, a plan to convert the schoolôs waste vegetable oil into biodiesel was initiated by two students in the Chemical Engineering Department. In addition to pure biodiesel, the process yields glycerin, which can be converted into a variety of useful products including soaps and candles. Graduate students from the School of Business were asked to analyze the biodiesel derivatives as part of their course requirement. More specifically, a feasibility analysis was performed on all possible biodiesel and glycerin products and their potential use on campus. This analysis examined the potential cost savings in manufacturing bar soap, liquid soap, candles, heating oil, and pure biodiesel. The report revealed that biodiesel used for the dormitory backup generators, liquid soap, and candles were the three most plausible biodiesel derivatives. The outcomes of this endeavor demonstrate the benefits of chemical engineering students working with business students. In addition, the experiences shared demonstrate the possibility of productive joint ventures between engineering and business programs at other institutions.

$\underline{\text { Introduction }}$
\end{abstract}

Rising fossil fuel costs increase the need for alternative fuels. Biodiesel is an alternative to petroleum that is made from natural feedstocks such as vegetable oil ${ }^{1}$. Biodiesel can, in some instances, be utilized petroleum-free. However, it can also be mixed with petroleum in order to decrease variability in its viscosity with differences in temperature. Typical blends include a two percent biodiesel/ninety-eight percent petroleum mix (B2), five-percent biodiesel/ninety-five percent petroleum mix (B5), twenty percent biodiesel/eighty percent petroleum mix (B20), and pure biodiesel (B100). B20 is the most common of these blends, as it retains the majority of the engineôs power ${ }^{2}$. On average, biodiesel produces 3.2 units of energy per gallon ${ }^{3}$. It is a clean burning fuel, which has significantly less carbon emissions when compared to petroleum. For example, a B20 blend decreases the carbon emissions by fifteen percent.

The governing reaction that converts waste vegetable oil to biodiesel is a transesterification reaction in which liquid alcohol (usually methanol or ethanol) and a base (usually sodium hydroxide or potassium hydroxide) is added to vegetable oil to produce biodiesel and glycerin ${ }^{4}$. Glycerin is a byproduct of the reaction that can be converted into soaps, candles and other products. Once the reaction is complete and the two products separated, the biodiesel has to be purified. One way to purify the biodiesel is by using water. Since biodiesel is a non-polar molecule, the polarity of the water attracts and removes any impurities from the biodiesel as the 
water separates from the biodiesel ${ }^{5}$. This washwater is then removed once it phase separates ${ }^{6}$. The second method of removing impurities from biodiesel is through the use of Magnesol DSol; a synthetic magnesium silicate powder ${ }^{7}$. The impurities in the biodiesel attach to the powder as it is suspended in the liquid. This filtering powder does not settle out, and as such, an additional filtration step is necessary to remove it.

The majority of biodiesel is made from vegetable cooking oil, though others may be used. Examples include: plant oils such as peanut oil, animal oils such as animal fats, and any cooking oil ${ }^{8}$. Each of these oils contains long fatty acid chains and esters that can be converted into biodiesel. Some of these oils have more of these molecules than vegetable oil, but vegetable oil is much more commonly used due to its abundance and low cost.

\section{$\underline{\text { Background }}$}

Biodiesel production is part of a sustainability movement that is occurring throughout the country. It is a movement that many colleges and universities are beginning to participate and implement green methodologies. XXXXX College is among these schools, and has been conducting research in the production of biodiesel and the utilization of both the biodiesel and glycerin products around campus. Other institutions who are active in biodiesel research include: Tufts University, University of Missouri and Pennsylvania State University.

Tufts University has a large sustainability program with an interest in biodiesel production. Although the primary focus of the universityôs biodiesel research is implementation beyond the campus, Tufts has looked into the production of biodiesel to use in university vehicles ${ }^{9}$. The school also proposed a plan for biodiesel production in Turkey in an attempt to minimize contributions to global warming ${ }^{10}$. As a result, the proposal turned into a large scale production business plan that was analyzed in terms of marketing, operating, and finances ${ }^{11}$. In addition, a biodiesel processor feasibility study was conducted to determine how beneficial the production of biodiesel is. Substantial research in the efficiency or cost analysis of using biodiesel as an alternative fuel was not performed, nor was a plan proposed to incorporate all aspects of the campus into the production of biodiesel.

At the University of Missouri, Schumacher is the primary investigator in the field of biodiesel. His research in biodiesel revolves around soybean oil as the feedstock. Initially the difference in quality of different blends of biodiesel was analyzed ${ }^{12}$. Some research was then conducted on fueling heavy duty diesel engines with the soybean oil ${ }^{13}$. Schumacher then started to focus on the use of biodiesel in public transportation, in particular buses ${ }^{14,15}$. In addition, the amount of emissions exerted by two different engines, the Series 60 DDC engine ${ }^{16}$ and the Cummins L10E engine ${ }^{17}$ were studied to analyze significant decreases in emissions. Recently, an analysis of the engine oil was performed on the buses using different blends of the soybean oil biodiese $^{18}$. Although the University of Missouri has performed a great deal of studies in the efficiency of the biodiesel fuel as well as in the amount of emissions, its focus is primarily on the use of biodiesel in buses. The research does not incorporate the effect and benefits of biodiesel use throughout the universityô campus.

The Pennsylvania State University has built a biodiesel pilot plant designed for batches 
of 25 gallons. The research conducted at this plant centers around: the biodiesel reaction at room temperature, methanol recovery, the use of a thermoelectric condenser and a new small scale reactor, the effects of additives on the pour point of the biodiesel, and the flash point and quality of the biodiese ${ }^{19}$. Research was also conducted on the use of camilina oil as a starter material for biodiesel. The university also intended on using the waste cooking oil from the school cafeterias to produce biodiesel. However, there is no concrete plan on implementation.

\section{Methodology}

The biodiesel initiative at XXXXX College began as an independent research project involving two Chemical Engineering students. They were tasked with finding a production method and a plan for third world nations to be able to produce enough biodiesel to provide a sufficient amount of energy for several applications. The biodiesel was produced from both virgin vegetable oil and waste cooking oil from the collegeôs cafeterias and was analyzed through collaboration with the Mechanical Engineering department. This was done using a Lister engine to determine the efficiency of both virgin and waste vegetable oil biodiesel when compared to standard petroleum fuel. Studies were performed on the purity of the biodiesel and fuel efficiency when varying the alcohol and base.

This initial research project evolved into another independent project involving four Chemical Engineering students that focused on the conversion of glycerin into other useful products. Some products that can be manufactured from glycerin are: bar soap, liquid soap, and candles. These projects evolved into a collaboration between the Chemical Engineering undergraduates, and graduate students from the School of Business to produce a cost and feasibility analysis on the products from the biodiesel reaction. These products have the potential to impact several constituents of the college.

The biodiesel initiative for XXXXX College became more popular after Hurricane Sandy hit New York City. During the storm, a power line was torn down which result in the loss of power in two buildings on campus; one of which was a dormitory. The dormitory was forced to run on the backup generator for two weeks while power was being restored. There was temporary power in the hallways and in the lobby to provide power for the elevators but the students living in that building did not have power in their rooms due to the limited supply of resources in the area, and high cost of operating the generator at full capacity. The proposed plan would have provided more than enough biodiesel to be used in the generators for them to run at full capacity while the power was being restored. Instead of converting the cooking oil from the cafeterias into fuel, the college had to pay for regular fuel for the generators.

$\underline{\text { Results }}$

The analysis of biodiesel production was first performed to determine if production would be useful to the College. One obvious benefit is the disposal of waste vegetable oil from the cafeterias. More specifically, dining services has to pay an outside company to come and remove the used oil. By taking the used cooking oil from the cafeterias, there is an immediate savings by eliminating the cost of disposal. Additionally, the production of biodiesel from spent cooking oil decreases the amount of oil that ends up in landfills, thus minimizing waste. 
A feedstock analysis was next performed to forecast the expected outputs from the biodiesel process. The four cafeterias at XXXXX College generate 220 gallons of waste vegetable oil each month. With a conversion of approximately $70 \%, 150$ gallons of biodiesel can be produced every month. The school is in full operation for seven out of twelve months, bringing the total amount of possible biodiesel produced to 1050 gallons for the college to use in campus vehicles or as heating oil. The remaining 70 gallons are converted into glycerin and could be made into bar soap, liquid soap, and/or candles.

The first application analyzed by the feasibility study was the use of the biodiesel for campus vehicles. According to the College, the majority of campus vehicles are used by the security department, all of which were recently replaced with models that are fueled with gasoline. Because this was a recent purchase, plans to replace them with vehicles that use diesel fuel will unfortunately not occur in the near future. As a result, this option turned out not to be a feasible option.

The next application was the use of heating oil for the backup generators. With 1050 gallons of biodiesel available, it was determined that the generators at all four of the dormitories would be able to run at the same time at full capacity for at least two days straight. During unfortunate and unforeseeable events such as Hurricane Sandy, this application would have saved the college a significant amount of money. The biodiesel could be blended with petroleum fuel to make the biodiesel last even longer, which would still decrease the current cost of fueling the generators. The cost of producing biodiesel from the cooking oil is significantly less than that of acquiring petroleum diesel needed for the generators, making this application a rather feasible one.

Bar soap was another application of the biodiesel process that was analyzed. Bar soap is a product of a saponification reaction where glycerin is reacted with sodium hydroxide to make soap. In order to make bar soap from the glycerin, the glycerin needs to be purified from any excess methanol before it can be molded. Because methanol has a low boiling point of $65^{\circ} \mathrm{C}$ (or $149^{\circ} \mathrm{F}$ ), heating up the glycerin beyond these temperature will effectively remove the methanol. The issue lies in the use of sodium hydroxide. Even though sodium hydroxide is the necessary reactant, it does not react as well with glycerin as it would with vegetable oil. The resources required in both time and materials to produce an acceptable quality solid bar of soap indicated that the break-even point was beyond the capacity of the school (i.e. the cafeterias would not be able to provide enough used vegetable oil to make this product profitable).

After analyzing bar soap, liquid soap was analyzed for feasibility. Liquid soap also goes through a saponification reaction as did the bar soap once the methanol is removed. For liquid soap, however, potassium hydroxide is used in the reaction as opposed to the sodium hydroxide used for bar soap. When the saponification reaction is completed, the products are further cooked to maintain the soap in liquid state. In the feasibility analysis, the liquid soap would be used to stock the soap dispensers throughout the campus buildings. There are a total of 75 soap dispensers on campus which require 172 cases of soap containing six liters of soap each per year. Each case costs the school $\$ 42.50$ which makes the total cost of soap $\$ 7,310$ per year for the campus. The ratio of reactants to product made was scaled up to account for the total amount of soap needed to provide the college with soap for a year. The relevant data for the cost analysis 
is shown in Table 1.

Table 1. Cost to Produce Liquid Soap on Campus

\begin{tabular}{|l|l|l|l|}
\hline Item & Quantity & Price & Total \\
\hline Plastic Soap Dispenser & 75 & $\$ 3$ & $\$ 225$ \\
\hline Total Packaging Costs & & & $\$ 225$ \\
\hline Glycerin & $500 \mathrm{~L}$ & $\$ 0$ & $\$ 0$ \\
\hline Water & $250 \mathrm{~L}$ & $\$ 0$ & $\$ 0$ \\
\hline Potassium hydroxide (2lbs) & 60 & $\$ 8$ & $\$ 480$ \\
\hline Lavender Scent (1lb) & 16 & $\$ 27$ & $\$ 432$ \\
\hline Total Materials Cost & & & $\$ 912$ \\
\hline Total Cost & & & $\$ 1,137$ \\
\hline
\end{tabular}

Based on this table, the total cost of manufacturing liquid soap from glycerin comes out to be $\$ 1,137$, approximately one seventh of the cost of buying liquid soap each year. This option saves the college $\$ 6,173$ per year. After five years the college will end up saving over $\$ 30,000$.

One issue arises from the fact that the current method for making the soap takes 45 minutes from start to finish and produces only three liters of soap. One proposed solution is for the college to hire its students under work-study to produce the soap. The cost of hiring students to make soap is shown in Table 2 .

Table 2. Cost to Employ Students to Make Soap.

\begin{tabular}{|l|l|}
\hline Amount of Soap Needed & $1032 \mathrm{~L}$ \\
\hline Total Number of Batches & 344 \\
\hline Total Number of Work Hours & 258 \\
\hline Total Employee Cost & $\$ 1870.50$ \\
\hline
\end{tabular}

From the table above, the total cost of hiring students to produce the needed soap from the school comes out to $\$ 1870.50$. Even with this additional cost, the final cost to produce soap for the whole campus is $\$ 3,007.50$. With this option the college still saves $\$ 4,302.50$ per year, making it an extremely feasible option.

The last option in the feasibility study was the manufacture of candles. The components of a candle include the wax, wick, color, fragrance, and jar, which is more material than what goes into making any of the other biodiesel derivatives. To make the wax, the glycerin has to be melted down to a liquid. Color in the form of either a pigment or a dye along with the fragrance is added to the melted glycerin. The wick is then placed into the jar and the wax is poured in and set aside to cool. A major obstacle in the candle venture is that they are not allowed in any of the dormitories at this particular school as they are deemed a fire hazard. As a result, the manufactured candles would only be sold on holidays or before breaks. Based on the typical costs of materials for making candles, a cost analysis is shown in Table 3 
Table 3. Cost to Produce an eight oz. candle.

\begin{tabular}{|l|l|l|l|}
\hline Material & Amount Needed & Cost per unit & Total Cost \\
\hline Wax & 8 oz. & $\$ 0$ & $\$ 0$ \\
\hline Wick & 3 in & $\$ 0.33 /$ yard & $\$ 0.03$ \\
\hline Fragrance & 0.4 oz. & $\$ 2.99$ & $\$ 1.20$ \\
\hline Color & 0.1 block & $\$ 0.89$ & $\$ 0.09$ \\
\hline Jar & 1 & $\$ 2.00$ & $\$ 2.00$ \\
\hline Total cost & & & $\$ 3.32$ \\
\hline
\end{tabular}

Assuming that the candles being manufactured are the smallest typical size, eight oz., the total cost to manufacture candles would be $\$ 3.32$ per candle. If the candles were sold at $\$ 5.00$ per candle there would be a profit of $\$ 1.68$ per candle. It was determined that a total of 2586 candles would be needed every year but with supply of glycerin from the biodiesel process, only 1584 candles can be made every year. Assuming that the candles would be sold at $\$ 5$ a candle the total revenue from this option is $\$ 2661.12$. This option turns out to be a feasible option that can provide the school with a profit of $\$ 2661.12$.

\section{Conclusion}

The biodiesel production process at XXXXX College was utilized to produce not only biodiesel but also several useful products from the glycerin byproduct. A feasibility analysis was performed to determine the best possible uses for both the biodiesel and the glycerin. The possible options included using the biodiesel for campus vehicles, as heating oil for the backup generators, and converting the glycerin into bar soap, liquid soap, and candles. The feasibility report took into consideration not only the demand of the different options, but also the supply of raw materials, the cost to manufacture, and the process through which each is produced.

The use of biodiesel for campus vehicles turned out to be unfeasible for the sole reason that the school recently replaced the campus vehicles with gasoline-fueled models. The heating oil for the generators, on the other hand, is a feasible option. From the current supply of vegetable oil from the cafeterias, enough biodiesel can be produced to power all of the generators for two days continuously. This will reduce the cost of fueling, especially during disasters like Hurricane Sandy, where the cost of fuel is high and its availability can be scarce.

In terms of the biodiesel derivatives from the glycerin, the feasibility report showed the bar soap to be unfeasible. The process by which the soap was to be produced proved to be too time consuming and complicated with an inconsistent product quality. The liquid soap, although using a similar process, turned out to be quite feasible. The liquid soap manufactured from the supply of glycerin would be enough to supply all the soap dispensers at XXXXX College each year. The issue of the amount of time consumed in manufacturing liquid soap can be addressed by hiring students to manufacture the soap. Even with the added cost of paying students for labor, the college would end up saving over $\$ 4,000$, annually. Lastly, the candles ended up being unfeasible. The total cost of manufacturing the candles was $\$ 3.32$ per candle which would still bring in a profit to the college; however, the issue was in the lack of demand. The estimated supply of candles was 1584 candles per year while the estimated demand was 
2586 candles. Based on the higher demand for candles than the supply, revenue of at least $\$ 2661.12$ per year should be expected.

By incorporating the School of Business into the project from the Chemical Engineering Department, a real-world analysis was performed. The process of producing biodiesel was analyzed not only by yield amount, but also for the feasibility of producing each product. This collaboration was extremely beneficial on both sides. This is because an engineer can gain from the practical viewpoint of a business student, and a business student can gain from the technical viewpoint of an engineer.

Chemical engineering faculty can similarly partner with business students at their own institution. Mutually beneficial activities can stem from independent research projects such as those described in this work, or incorporated into courses such as plant design where an economic component is involved. Chemical engineering students benefit from the analytical strategies not typically taught in an engineering economics course, while business students are exposed to technologies they may not normally encounter. Interdisciplinary interactions such as these not only have potential to benefit your institution, but help expand the skill set of the students who participate.

\section{Future Work}

With the knowledge of which biodiesel products are most feasible, a plan for action needs to be determined. In terms of the 1050 gallons of biodiesel that will be produced to act as heating oil for the generators, a few decisions need to be made. The major decision is to determine where the biodiesel will be stored when it is not being used, and assuming that power outages will not be common all 1050 gallons will have to be stored at the same time. In addition, the cost of storage needs to be determined. A schedule will need to be made that will sync the production of biodiesel with the intended removal of used cooking oil from the cafeterias. A schedule for production of both the liquid soap will also be necessary to make sure enough soap is produced for when it is needed. The candle production will need a schedule so that there are enough candles for students to purchase before the holiday season begins and classes end. Perhaps, in the future, the option of incorporating diesel powered campus vehicles can be revisited.

\section{References}

1 "Straight Vegetable Oil as a Diesel Fuel?" Energy Efficiency \& Renewable Energy. N.p., n.d. Web. 13 Mar. 2013. <http://www.afdc.energy.gov/pdfs/47414.pdf>.

${ }^{2}$ Catalano, G., J. Fernandes, C. Frazer, and B. Korney (2012, April 30). XXXXX College Biodiesel Fuel: A Feasibility Study. School of Business, XXXXX College. Riverdale, NY. Retrieved December 28, 2012, from Yassir Samra. ${ }^{3}$ Alternative Fuels. Office of Sustainability: Tufts University. Boston, MA. Retrieved December 28, 2012, from
http://sustainability.tufts.edu/alternative-fuels/.

\footnotetext{
${ }^{4}$ Romero, Rubi. "Biodiesel Production by Using Heterogeneous Catalysts." (n.d.): n. pag. Web. 13 Mar. 2013.
} <http://cdn.intechopen.com/pdfs/17583/InTech-Biodiesel_production_by_using_heterogeneous_catalysts.pdf>. 
${ }^{5}$ Rickdatech. "Intro to Water Washing | Water Washing." Intro to Water Washing | Water Washing. N.p., n.d. Web. 14 Mar. 2013. <http://make-biodiesel.org/Water-Washing/>.

${ }^{6}$ Rickdatech. "Mist Washing Biodiesel." Mist Washing Biodiesel | Water Washing. Make Biodiesel, n.d. Web. 14 Mar. 2013. <http://make-biodiesel.org/Water-Washing/mist-washing-biodiesel.html>.

${ }^{7}$ Rickdatech. "Dry Wash Biodiesel with Magnesol | Waterless Washing." Dry Wash Biodiesel with Magnesol $\mid$ Waterless Washing. N.p., n.d. Web. 14 Mar. 2013. <http://make-biodiesel.org/Waterless-Washing/dry-washbiodiesel-with-magnesol.html>.

${ }^{8}$ Canakci, M. "BIODIESEL PRODUCTION FROM OILS AND FATS WITH HIGH FREE FATTY ACIDS." N.p., n.d. Web. 13 Mar. 2013. <http://seniordesign.engr.uidaho.edu/2007_2008/frenchfryfuel/paper_2.pdf>.

${ }^{9}$ Dulgarian, J., A. Narang, F. Parent, and T. Pietro (1997, May 1) Alternative Fuels in the Tufts University Vehicle Fleet. Tufts University. Boston, MA. Retrieved December 28, 2012, from http://sustainability.tufts.edu/wpcontent/uploads/UpdatedListofStudentProjects.pdf.

${ }^{10}$ Aktar, M. Biodiesel Production in Turkey. The Gordon Institute of Tufts Universit,: Tufts University. Boston, MA. Retrieved December 28, 2012, from gordon.tufts.edu/engMgmt/MSEM/projectBiodieselStatement.pdf.

${ }^{11}$ Aktar, M. Altintel A.S.Business Plan for Large Scale Biodiesel Production in Turkey. The Gordon Institute of Tufts University: Tufts University. Boston, MA. Retrieved December 28, 2012, from http://gordon.tufts.edu/engMgmt/MSEM/projectBiodieselBusinessPlan.pdf.

${ }^{12}$ Schumacher, L. G., S.C. Borgelt, and W.G. Hires. (1993). Soydiesel/Petroleum Blend Research. Proceedings of the American Society of Agricultural Engineers Winter Meeting. Chicago, IL. ASAE Paper No. 936523. Retrieved December 28, 2012, from http://web.missouri.edu/ schumacherl/biofuel.html.

${ }^{13}$ Schumacher, L. G., S.C. Borgelt, D. Fosseen, W. G. Hires, W. Goetz (1994) Fueling Diesel Engines with Blends of Methyl-Ester Soybean Oil and Diesel Fuel. Biodiesel '94. Sioux Falls, SD. Retrieved December 28, 2012, from http://web.missouri.edu/ schumacherl/Fueling_Diesel_Engines_with_Blends_of_Methyl_Ester_Soybean_Oil.pdf.

${ }^{14}$ Schumacher, L. G. and J.A. Weber (1994). Collection and Collation of Performance Data From Urban Mass Transit Biodiesel Demonstrations. Proceedings of an Alternative Energy Conference, American Society of Agricultural Engineers Summer Meeting. Kansas City, MO. Retrieved December 28, 2012, from http://web.missouri.edu/ schumacherl/Collection_and_Collation_of_Performance_Data.pdf.

${ }^{15}$ Chandler, K., N. Malcosky, K. Kelly, P. Norton, R. Motta, L. Schumacher, \& D. Lyons. (1996) Alternative Fuel Transit Bus Evaluation Program Results. International Spring Fuels and Lubricant Meeting. Dearborn, MI. SAE Paper No. 961082. Retrieved December 28, 2012, from http://web.missouri.edu/ schumacherl/Collection_and_Collation_of_Performance_Data.pdf.

${ }^{16}$ Schumacher, L G. (1995). Biodiesel Emissions Data From Series 60 DDC Engines. American Public Transit Association Bus Operations and Technology Conference. Reno, NV. Retrieved December 28, 2012, from http://web.missouri.edu/ schumacherl/Collection_and_Collation_of_Performance_Data.pdf.

${ }^{17}$ Marshall, W., Schumacher, L.G, Howell, S. A (1995) Engine Exhaust Emissions Evaluation of a Cummins L10E When Fueled with a Biodiesel Blend. SAE Paper No. 952363. SAE, Warrendale, PA. Retrieved December 28, 2012, from http://web.missouri.edu/ schumacherl/Collection_and_Collation_of_Performance_Data.pdf.

${ }^{18}$ Schumacher, L.G. and J.V. Gerpen. (2000). Engine Oil Analysis of Diesel Engines Fueled with 0, 1, 2, and 100 Percent Biodiesel. Proceedings of the American Society of Agricultural Engineers International Meeting. Milwaukee, WI. ASAE Paper No. 006010. Retrieved December 28, 2012, from 
http://bengal.missouri.edu/ schumacherl/Engine_Oil_Analysis_of_Diesel_Engines_Fueled_with_0,1,2,100_Biodies el.pdf.

${ }^{19}$ Biodiesel Research Group. Department of Chemical Engineering, Pennsylvania State University. Retrieved December 28, 2012, from http://www.che.psu.edu/biodiesel/research.html 